\title{
Sistema de exercício online para apoio a aprendizagem de Medicina Legal na Universidade de Brasília
}

\author{
On line exercise systems to learning in Forensic \\ Medicine at the University of Brasilia
}

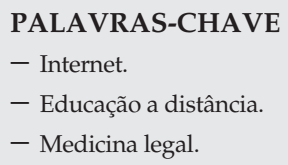

\begin{abstract}
R E S U M O
O propósito deste estudo retrospectivo foi avaliar o padrão de utilização do sistema de exercícios on-line, facultativos, assíncronos, para o apoio à aprendizagem da disciplina Medicina Legal e Deontologia Médica na Universidade de Brasília. Os sujeitos foram 38 alunos que cursaram a disciplina no segundo semestre de 2005. O sistema oferecia conteúdos textuais e imagens que podiam ser acessados anonimamente. Para a resolução dos exercícios do tipo "verdadeiro" ou "falso", alguns com imagens, era necessário que os alunos se identificassem por senha, o que permitiu o monitoramento. Os resultados mostraram que 32 alunos (84\%) realizaram exercícios on-line, com uma média de 183 respostas por aluno, entre os que aderiram; 52\% dos exercícios foram resolvidos nas últimas 24 horas antes da prova; $62,3 \%$ dos exercícios foram resolvidos entre 19he 01h. Conclui-se que os alunos, num sistema facultativo, concentram seus esforços na véspera da prova, o que diminui a eficiência do sistema, sugerindo que técnicas de motivação para o uso regular desse tipo de sistema devem ser implementadas.
\end{abstract}

\section{A B S T R A C T}

The purpose of this retrospective study was to evaluate the usage patterns with the system of online optional asynchronous exercises to support the learning of Forensic Medicine and Medical Ethics at the University of Brasilia. The subjects were 38 students taking this course during the second term of 2005. The system offered text content and images that could be accessed anonymously. To solve the "true-or-false" exercises, some with images, students had to self-identify by means of a password, which allowed tracking. The results showed that 32 students (84\%) performed exercises online, with an average of 183 responses per student among those who joined. Slightly more than half (52\%) of the exercises were solved in the last 24 hours before the course test; $62.3 \%$ of the exercises were solved between 7 PM and 1 AM. In conclusion, students used a voluntary system to concentrate their efforts just before course tests, which reduces the system's efficiency, suggesting that techniques to motivate regular use of systems like this one should be implemented.

\footnotetext{
${ }^{I}$ Universidade de Brasília, Distrito Federal, Brasil.
} 


\section{INTRODUÇÃO}

O conhecimento humano atual na área da saúde é complexo e engloba diferentes ciências - biológicas, exatas e humanas ${ }^{1}$ - e sua apreensão exige a utilização de todos os recursos pedagógicos disponíveis.

Na década de 1970, programas informatizados passaram a ser utilizados para desenvolver habilidades específicas de leitura, escrita e noções matemáticas. O advento dos computadores pessoais em 1981 permitiu que, na década de 1980, os educadores vislumbrassem nos editores de texto uma poderosa ferramenta para a criação de material didático, registro de notas e pesquisas. A invenção do CD-ROM em 1985 ampliou muito a disponibilidade e variedade de informações, possibilitando implantar laboratórios de informática nas escolas. Surgiram diversos softwares educacionais multimidiáticos, explorando sons e imagens animadas para despertar o interesse dos alunos. A internet, disponível no Brasil a partir de 1986, assumiu, em apenas quatro anos de existência, o status de ferramenta universal de comunicação e de pesquisa ${ }^{2}$.

Os educadores concentraram-se na investigação de estratégias para a sua utilização, desenvolvendo atividades sincrônicas e assincrônicas, criando comunidades virtuais de aprendizagem, cursos à distância e portais com conteúdos educacionais.

Assim, o grande desafio foi identificar como os professores utilizariam as novas tecnologias de informação e comunicação em suas práticas pedagógicas. $^{2}$

O Ministério da Educação quer expandir o ensino superior a distância, como sinalizou em matéria publicada:

Num primeiro momento, nem todos os cursos poderão ser oferecidos a distância, pela complexidade do ensino-aprendizado. Somente no futuro uma aula de anatomia médica, por exemplo, poderá ser transmitida por computador sem problemas. Já outras cadeiras de Medicina e todas as outras de um curso de licenciatura, por exemplo, podem ser oferecidas sem dificuldade. ${ }^{3}$

Sistemas para o apoio ao ensino pela internet têm sido desenvolvidos por grandes instituições nacionais públicas e privadas ${ }^{4,5}$. A Faculdade de Medicina da Universidade de Brasília anseia acompanhar este processo de evolução do método pedagógico. A criação da Faculdade de Medicina e a renovação de seu projeto pedagógico reconhecem novas demandas e necessida- des, entre as quais a "capacidade para utilizar novos recursos de informação e tecnologia"6, e recomenda "utilizar os procedimentos básicos de informática aplicáveis às múltiplas funções do médico" ${ }^{\prime}$.

Um sistema para o apoio ao ensino pela internet, além de influir diretamente na formação acadêmica, leva o graduando a compreender as possibilidades da internet, incorporando a prática de utilização desta poderosa ferramenta para toda a vida.

A diferença de custo entre publicações convencionais e digitais, especialmente com ilustrações coloridas, imprescindíveis ao ensino da Medicina Legal, constitui um forte argumento para o uso da internet. $\mathrm{O}$ armazenamento de informações verbais e visuais aumenta consideravelmente as chances de fixação das mesmas ${ }^{7}$.

O Anuário Brasileiro Estatístico de Educação Aberta e a Distância ${ }^{8}$ demonstrou que, em 2005, 1.278.022 brasileiros se instruíram por algum tipo de educação a distância (EAD); 217 instituições ofereceram aulas a distância, um crescimento de 30,7\% em relação ao ano anterior; 321 novos cursos a distância foram oferecidos, e 300.839 estudantes se matricularam em algum curso de ensino superior nesse ano (graduação, tecnológico, pós-graduação lato sensu e sequenciais).

EAD é expressão polissêmica, e a definição aplicável neste caso é a do Decreto $n^{\circ}$ 5.622/05, que regulamenta o art. 80 da Lei 9.394/96, que estabelece as diretrizes e bases da educação nacional:

Para os fins deste Decreto, caracteriza-se a educação a distância como modalidade educacional na qual a mediação didático-pedagógica nos processos de ensino e aprendizagem ocorre com a utilização de meios e tecnologias de informação e comunicação, com estudantes e professores desenvolvendo atividades educativas em lugares ou tempos diversos. ${ }^{9}$

Este trabalho tem como objetivos mensurar a utilização do sistema de exercícios on-line, facultativos e assíncronos, e determinar eventual padrão de utilização quanto ao tempo de duração da pesquisa, aos dias da semana e aos horários dos alunos que cursaram a disciplina Medicina Legal e Deontologia Médica na Universidade de Brasília no segundo semestre de 2005.

\section{MÉTODO}

O sistema de exercícios on-line utilizado é fruto da evolução permanente de um site criado em 1996 pelo autor, como uma subpasta de domínio de um provedor, utilizado para disponibilizar textos e imagens aos alunos. O crescimento progressivo do site justificou a criação de um domínio próprio a partir de 16/08/2000, disponível em http:/ / www.malthus.com.br, oportunidade em que foi implementado um sistema dinâmico aco- 
plado a um banco de dados. Este recurso pedagógico ainda está sendo utilizado, não só pelos alunos cadastrados, de graduação e de pós-graduação, mas, predominantemente, por usuários não cadastrados, de todo o Brasil e do mundo, que se interessam pelos temas Medicina e Odontologia Forenses.

O sistema para apoio ao ensino analisado, disponível na internet via www (World Wide Web), utilizou a tecnologia ASP (active servepages) Microsoft ${ }^{\circledR}$, que pode processar a requisição do usuário no próprio servidor, montar dinamicamente, a partir de um banco de dados, uma página personalizada no formato HTML (hipertext markup language) e enviá-la ao usuário. Pela programação, é possível realizar operações lógicas, cálculos, redirecionamentos, consultas e alterações no banco de dados, no caso o Access Microsoft ${ }^{\circledR}$. A programação ASP possibilita a inclusão de uma página dentro de outra, o que permite reaproveitar uma mesma rotina de programação em várias páginas diferentes. Esse recurso foi utilizado para incluir definição de variáveis, cabeçalho, rodapé e a programação para armazenar informações de todas as páginas visitadas, assim como horário inicial da visita, horário da requisição, endereço completo requisitado, IP (internet protocol) e código de usuário identificado, entre outros. Não se utilizaram cookies, para que os alunos pudessem usar diferentes computadores, sem perda de informações ou violação da privacidade.

As principais seções do sistema eram textos, na forma de tópicos hierarquizados e artigos, imagens, exercícios on-line e links.

$\mathrm{O}$ acesso aos textos e às imagens do sistema era livre a qualquer usuário, independentemente de cadastro prévio e identificação. A seção de exercícios on-line requeria a identificação do usuário, o que possibilitava a gravação das respostas num banco de dados. Por essa razão, a análise restringiu-se aos dados dessa seção. Os alunos podiam iniciar uma sequência de exercícios em determinada oportunidade e concluí-la noutra, pois a cada resposta ocorria a gravação no banco de dados.

No primeiro dia de aula, os alunos receberam, em papel, uma senha de acesso e explicações básicas sobre o sistema. Foi esclarecido que a utilização do sistema era facultativa e que não seria parte da avaliação da disciplina. O sistema foi comparado a "mais um livro disponível na biblioteca", cuja utilização não seria indispensável ao aluno. Contudo, vantagens como disponibilidade, custo, riqueza de ilustrações e exercícios on-line foram enfatizadas no primeiro dia. Não houve, ao longo do semestre, estimulação para o uso do sistema.

Ao receberem a senha de acesso, os alunos foram cientificados de que as informações de acesso seriam registradas e que, após o término do semestre e lançamento definitivo das menções, para diminuir ao máximo a vulnerabilidade dos sujeitos da pesquisa, apreciariam um Termo de Consentimento Livre e Esclarecido, conforme Resolução 196/96 do Conselho Nacional de Saúde ${ }^{10}$. Esta pesquisa foi aprovada pelo Comitê de Ética em Pesquisa Envolvendo Seres Humanos, da Faculdade de Medicina da Universidade de Brasília. Todos os alunos (38) aceitaram participar da pesquisa e assinaram o termo de consentimento.

A análise da utilização do sistema foi limitada ao período entre $14 \mathrm{~h}$ do dia 12/08/05, com a distribuição das senhas, e $12 \mathrm{~h}$ do dia 03/02/06, início da primeira avaliação de conhecimentos, ou seja, um intervalo de 175 dias. Em decorrência de greve, o semestre foi suspenso entre 06/09/05 e 03/01/06 (120 dias), período em que o sistema se manteve disponível normalmente.

Figura 1

Exibição parcial da tela para resolução de exercícios no modo "gabarito e justificativas".

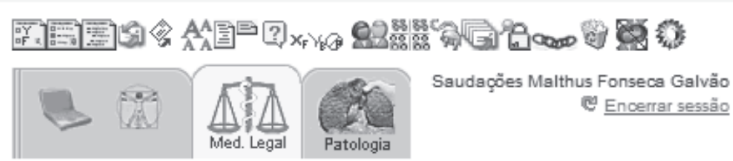

\section{Projetil de Arma de Fogo es}

Gabarito Gabarito e Justificativas Justificativas Sem nada

Quanto aos ferimentos por projeteis de arma de fogo, julgue os itens abaixo:

1)e ( $\backslash \bowtie)$ Gumercindo relatou que seu amigo Francinaldo se suicidou com um disparo de arma de fogo na cabeça, com o revólver encostado na testa. Seria razoável encontrar no Laudo Cadavérico o termo "Câmara de Mina de Werkengartner".

Falso, pois a Câmara de Mina é de Hoffman. Werkengartner é o epônimo para a marca da boca do cano aquecido.

2)e ( $)_{V}()_{F} \quad$ Os orificios de saida geralmente são maiores que os orificios de entrada.

3)e $(X) \vee$ É possivel que um orificio de saida apresente orla de escoriação. 
A seção de exercícios continha 670 itens do tipo verdadeiro ou falso, apresentados em conjuntos por assunto, alguns com comando agrupador, outros com imagens. Para resolver cada exercício, bastava clicar sobre a opção desejada, verdadeiro ou falso, e a resposta era gravada no banco de dados. Após esta ação, era possível visualizar a correção e as justificativas dos exercícios resolvidos e também corrigir ou apagar a resposta para refazê-los novamente.

Uma interface gráfica indicava, agrupados por assuntos, todos os exercícios por fazer, os já realizados, certos ou errados, e aqueles com as respostas apagadas, por indicação em barras coloridas de dimensões proporcionais.

Figura 2

Exibição parcial da tela para controle do aluno da resolução de exercícios, agrupados por assunto.

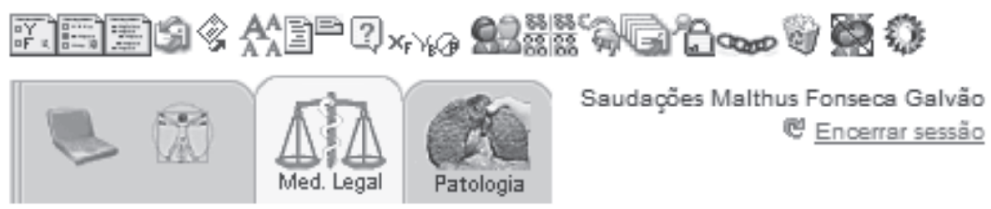

\section{[Y] Verdadeiro \& Falso क}

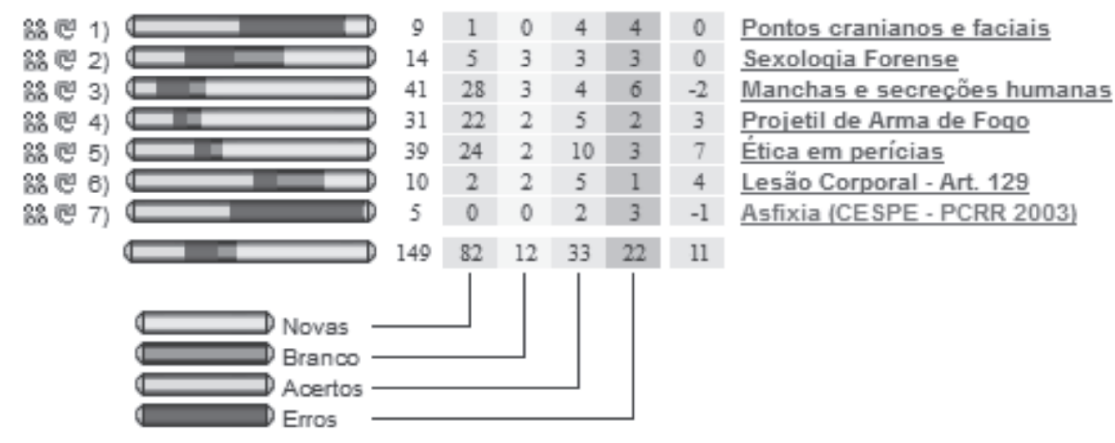

Da mesma forma que na tela anterior, existia outra tela que demonstrava de forma gráfica os totais de exercícios agrupados por aluno, possibilitando uma visão global da atividade da turma nos exercícios on-line.

\section{RESULTADOS}

Durante o período analisado, 05/08/05 14h a 03/02/06 12h, 1.026 .839 páginas do sistema foram acessadas por usuários, identificados ou não, com uma distribuição dia a dia demonstrada pela linha contínua em cinza na Figura 1. Dessas páginas acessadas, 456.609 (44,5\%) eram de imagens, 312.349 (30,4\%) de textos, 58.932 (5,7\%) de artigos e 198.949 (19,4\%) de outras seções.

Dos 38 alunos matriculados na disciplina, 35 (92,1\%) utilizaram o sistema pelo menos uma vez de forma identificada e 32 $(84,2 \%)$ resolveram pelo menos um exercício on-line.

O total de páginas acessadas pelos alunos enquanto identificados foi de 5.857 (41,7\%) para resolução de exercícios, 3.319 (23,6\%) para consulta a textos, 847 (6\%) para listagem dos exercícios e 4.019 (28,6\%) para outras seções, totalizando 14.042 acessos. Em média, portanto, cada aluno $(n=38)$ resolveu 154,1 exercícios. Caso consideremos apenas os alunos que responderam algum exercício ( $\mathrm{n}=$ 32), a média foi de 183,0 resoluções por aluno.
O total de exercícios on-line resolvidos por cada aluno ao longo do período foi variável de forma linear, como se observa na Figura 4, quando se ordenam crescentemente os alunos pelo número total de exercícios resolvidos.

Os totais de exercícios on-line resolvidos por todos os alunos, agrupados por hora e por dia da semana, encontram-se na Figura 5.

\section{ANÁLISE}

O gráfico de utilização do sistema pelos usuários, identificados ou não, demonstra alguns picos de utilização que merecem discussão (Figura 1). No dia 15/09/05, um único usuário não identificado requisitou 10.331 páginas, entre 09h31min43s e 16h02min19s, ou seja, uma página a cada 2,3s. O IP utilizado, “200.105.153.102", segundo o site Lacnic ${ }^{11}$, pertence à empresa Boliviana AES Communications Bolivia S.A. Portanto, trata-se, muito provavelmente, de uma visita automatizada, um robô de indexação, como o Google ${ }^{\circledR}$, que rastreou todo o site. O mesmo fenômeno foi observado no dia 23/08/05, quando outro usuário requisitou 2.997 páginas, com média de 2s por página. A importância maior deste gráfico é a demonstração de que o sistema não ficou um dia sequer indisponível durante o período analisado. 
Figura 3

Totais de páginas acessadas por usuários identificados ou não $(\mathrm{n}=1.026 .839)$ (linha cinza) e resolução dos exercícios on-line por períodos de $24 \mathrm{~h}$ anteriores à prova $(\mathrm{n}=5.857)$.

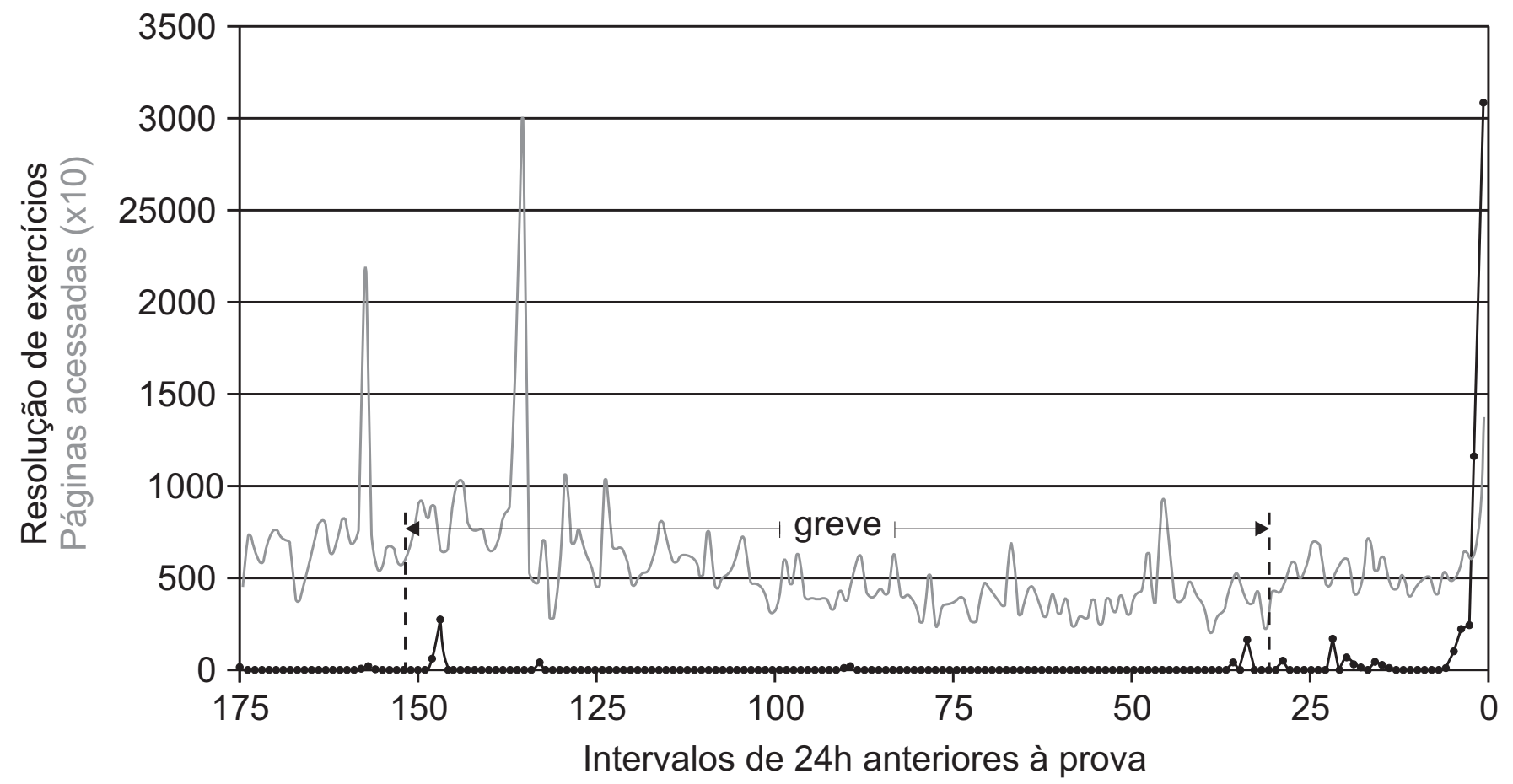

Figura 4

Número de exercícios on-line resolvidos por cada aluno, em ordem crescente.

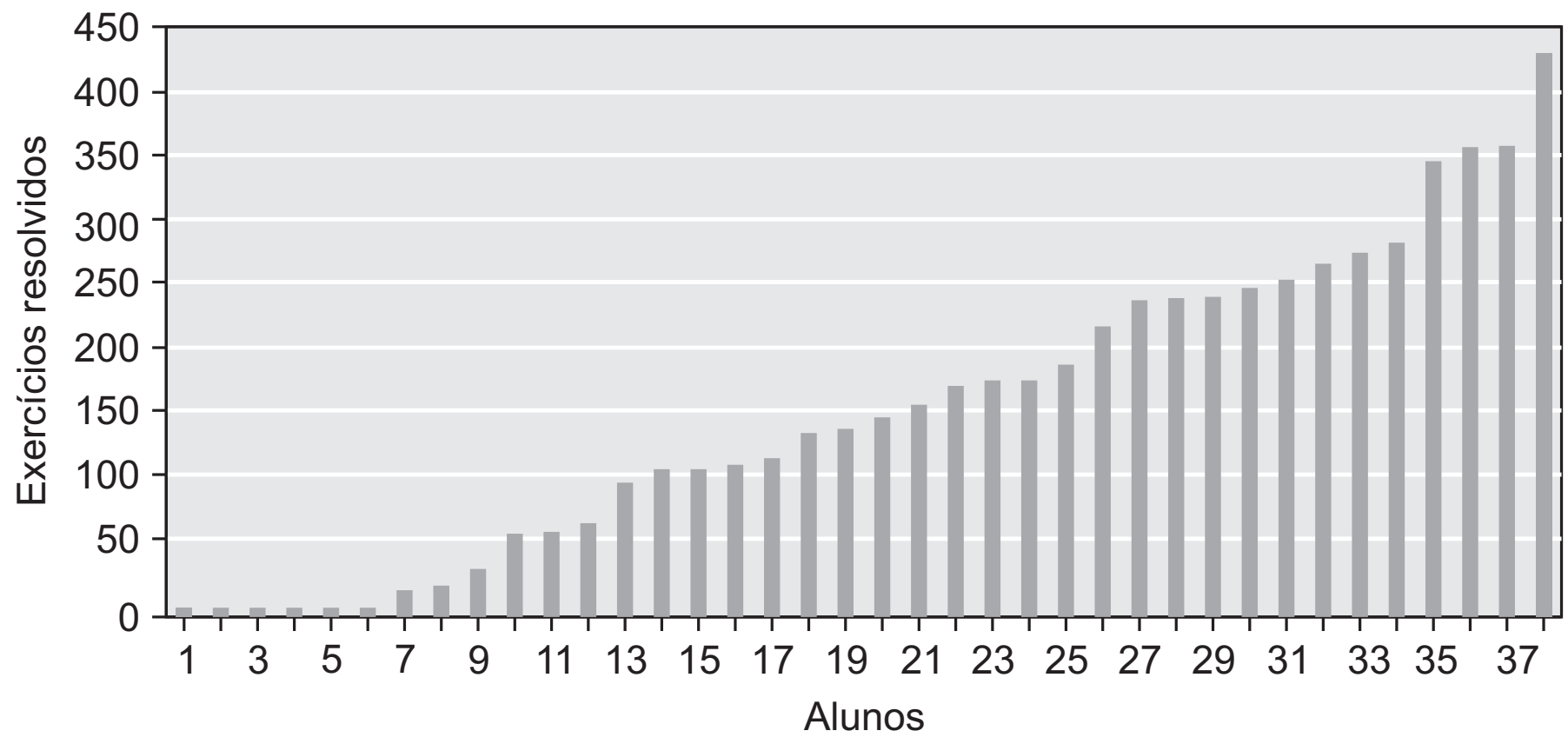


Figura 5

Resolução de exercícios on-line por dia da semana e por hora $(\mathrm{n}=5.857)$.

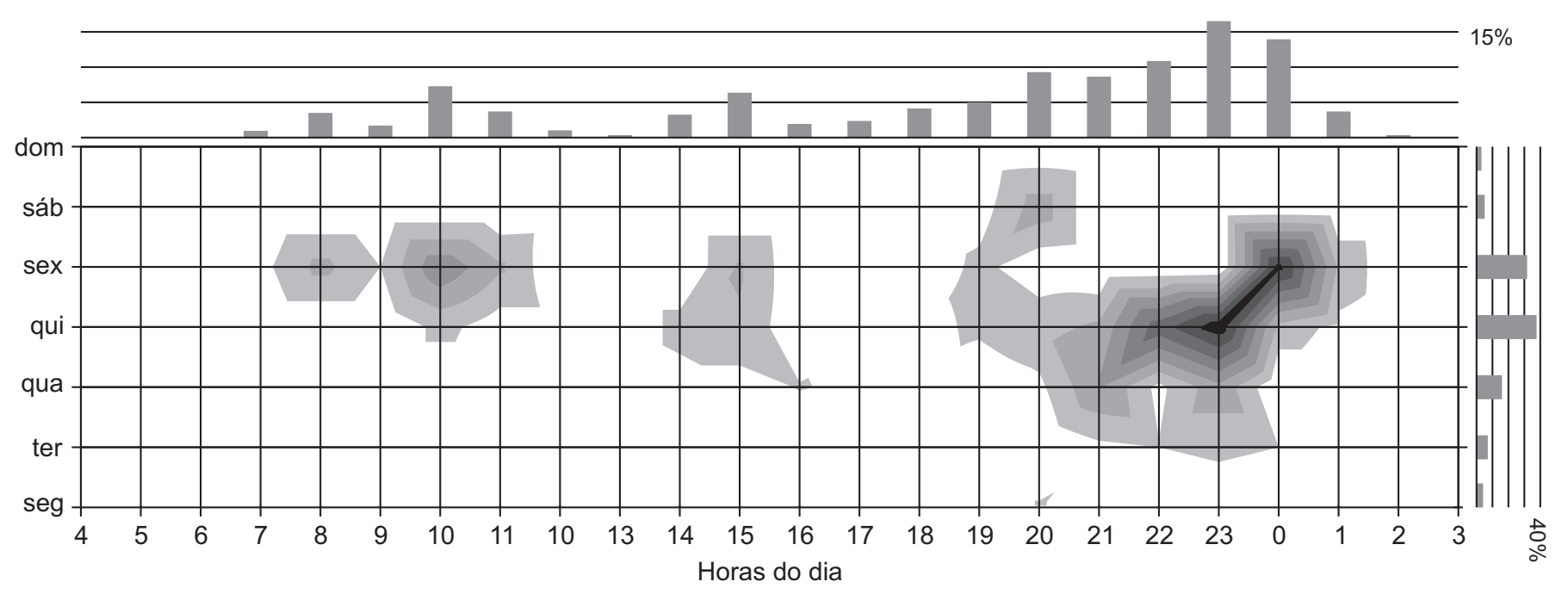

\begin{tabular}{|l}
$\square$ 0-80 $\square$ 160-240 $\square$ 320-400 $\square$ 480-560 \\
$\square$ 80-160 $\square$ 240-320 $\square$ 400-480 $\square$ 560-640 \\
\hline
\end{tabular}

As páginas mais visitadas pelos usuários, identificados ou não, foram as de imagens $(44,5 \%)$. Pode-se explicar este fato pela grande variedade de imagens disponíveis no site, mais de mil, pela pequena quantidade e baixa qualidade das ilustrações na maioria das publicações em Medicina Legal, pela quantidade de informações que uma imagem transmite, pelo interesse e por simples curiosidade. Às páginas de imagens, seguem-se as de textos, no formato de tópicos, cerca de 250, e as páginas de artigos, cerca de 150.

A análise restringiu-se à parte do sistema cujo acesso era concedido pela identificação - seção de exercícios on-line. Muitas vezes, o aluno navegava de forma não identificada e, após certo tempo de visita, identificava-se para ter acesso aos exercícios. O número registrado de páginas visitadas pelos alunos (14.042) é menor que o número real, número impossível de determinar.

Trinta e cinco dos 38 alunos da turma (92\%) utilizaram o sistema de forma identificada pelo menos uma vez, um número razoável, visto que o sistema é facultativo. Trinta e dois dos 35 alunos que utilizaram o sistema resolveram exercícios on-line, o que representa $91 \%$.

Fatores como disponibilidade de literatura convencional, acesso e capacidade para uso da internet, entre outros, não foram objeto de estudo desta pesquisa. É possível que um aluno, na véspera da prova, tenha se valido da senha de algum colega, por ter extraviado a sua própria.

O gráfico dos exercícios realizados pelos alunos, quando ordenado pelo número total de exercícios que cada um resolveu, forma praticamente uma reta inclinada, sem concentração alguma, onde a média de 183,0 exercícios/aluno, entre os que realizaram exercícios, não significa muito, posto que o desvio padrão foi de 127,3 .

A constatação mais importante desta pesquisa foi a prática do "estudo de última hora", que privilegia apenas a memorização imediata e quase nada acrescenta ao futuro desempenho profissional, pois o conhecimento "adquirido" será rapidamente apagado da memória. Nas últimas 24 horas que antecederam a prova, foram resolvidos $53,2 \%$ dos exercícios e, nas últimas 48 , $72,5 \%$. A variância do número total de exercícios resolvidos em cada um dos 175 períodos de 24 horas foi de 62.902,98 para um total de 5.857 exercícios. A distribuição foi extremamente leptocúrtica e com assimetria bem maior que zero, pois a utilização concentrada no final do período elevou muito a média $(33,5) \mathrm{em}$ relação à mediana (0). Essa constatação demonstra que os alunos não estão preparados para um sistema facultativo aplicado sem motivação constante ao longo do semestre. Fenômeno seme- 
lhante foi constatado por Coeli et al. ${ }^{12}$ : $44,7 \%$ dos acessos ao site Epidemio On-Line ocorreram nas semanas que antecederam as avaliações do curso.

A memória a longo prazo é armazenada de duas maneiras: semântica ou episódica. A memória episódica se relaciona à experiência de vida pessoal e de eventos; já a memória semântica abrange o conhecimento que temos sobre palavras, idiomas, símbolos, significados, relações entre os conhecimentos e regras para utilizar e manipular esses conhecimentos ${ }^{7}$.

Os principais modelos que tentam explicar a memória a longo prazo são: o Modelo de Cadeia, proposto em 1969 por Alan Collins e Ross Quillan; o Modelo Conjunto-Teórico, proposto em 1970 por David Mye; e o Modelo de Característica-Comparação, proposto em 1974 por Smith, Shoben e Rasgos em 1974. Em todos os modelos, o fenômeno conhecido como long-term potentiation se aplica, e a repetição e a recuperação da informação a tornam cada vez mais permanente. Para este efeito, 60 minutos de estudos são mais eficazes se distribuídos em quatro dias ${ }^{7}$.

Um erro frequente observado neste estudo é a procrastinação, que leva o aluno a acumular os estudos na véspera das provas.

Parte dos estudantes deixa para estudar na véspera da prova, virando noites antes da entrega de um trabalho, memorizando apenas, sem apreender ou assimilar o significado do conteúdo oferecido, o que é um erro. ${ }^{13}$

O estudo na véspera da prova está sujeito ao bloqueio emocional que chamamos de branco. Não há retenção na região do cérebro dedicada à memória de longo prazo. ${ }^{14}$

A Faculdade de Medicina da Universidade de Brasília esteve em greve a partir do dia 06/09/05, retomando suas atividades no dia 03/01/06. Foram 120 dias de greve. A disponibilidade do sistema durante a greve revelou-se uma vantagem a mais. No quinto e sexto dias de paralisação, houve um aumento significativo na resolução de exercícios, 53 e 260, respectivamente, o mesmo ocorrendo no quarto e sexto dias anteriores ao término da greve, 162 e 40 , respectivamente. No meio do período de greve, a utilização foi nula, com exceção do $20^{\circ}$ e do $63^{\circ}$, com resolução de exercícios reduzida, 43 e 21, respectivamente. Entre os dias supracitados, a média de utilização diária, 4,78 exercícios / dia, foi superior ao período anterior à paralisação, 3,2 exercícios/dia. Durante a interrupção do semestre, 8 alunos (21,1\%) resolveram exercícios (Figura 3).

O total de exercícios resolvidos por horas do dia demonstra um padrão compatível com a disponibilidade dos alunos de Medicina, geralmente ocupados durante o dia. A partir das 18h, a utilização cresceu paulatinamente até atingir um pico, por volta das 23h. Decresceu abruptamente após a meia-noite e atingiu quase zero durante a madrugada. Durante o turno noturno, entre $19 \mathrm{~h}$ e $1 \mathrm{~h}$, a utilização foi de $62,3 \%$. Dois picos menores ocorreram às $10 \mathrm{~h}$ e às $15 \mathrm{~h}$ (Figura 5).

O total de exercícios resolvidos por dia, ao longo da semana, evidencia uma curva de ascensão e descenso. A menor utilização ocorreu no domingo e a maior na quinta-feira (38\%) anterior às aulas, seguida pela sexta-feira (31,5\%). No sábado e domingo, embora presumida maior disponibilidade dos alunos, ocorreram as menores médias de resolução diária de exercícios (Figura 5).

A análise combinada dos dias da semana e das horas do dia mostra uma concentração na resolução de exercícios na noite anterior, quinta-feira, por volta das $23 \mathrm{~h}$. Outro pico de utilização ocorreu por volta das $10 \mathrm{~h}$ de sexta-feira e se relaciona ao intervalo das atividades da manhã do dia da aula, que se iniciava às $12 \mathrm{~h}$ (Figura 5).

A análise temporal do uso do sistema mostra a necessidade de maior estímulo, por parte dos professores, para uma utilização constante ao longo do curso, possivelmente associada aos critérios de avaliação ${ }^{15}$. Esse controle é extremamente fácil, pois o sistema apresenta uma tela na qual é possível, a qualquer momento, gerar um relatório gráfico que demonstra o acesso e as respostas de cada aluno ao longo do período. Outra forma de estímulo, não vinculada à menção, é a apresentação, ao início de cada aula, dos gráficos diários, semanais e acumulados da utilização do sistema, individuais (Figura 2) e coletivos, e questionamento sobre os motivos de eventual não uso satisfatório.

Para evitar que os alunos se concentrem na resolução dos exercícios na véspera da prova, estes deveriam ser disponibilizados por etapas, ao longo do semestre.

Sempre que a frequência a uma aula é baixa, a justificativa alegada é a ocorrência de avaliações de outras disciplinas. Contudo, é possível programar o sistema para indisponibilizar os exercícios durante outras atividades acadêmicas importantes.

\section{CONSIDERAÇÕES FINAIS}

A maioria dos alunos da disciplina utilizou o portal de Medicina Legal (92\%), e muitos resolveram exercícios on-line (84\%), apesar de facultativos. Isso demonstra que os alunos têm interesse, conhecimento e acesso à internet. Portanto, essa ferramenta deve ser cada vez mais explorada.

Esta pesquisa também constatou uma extrema concentração de acesso ao sistema na véspera da prova, com resolução de $52 \%$ dos exercícios nas últimas 24 horas. A procrastinação nos estudos diminui a eficiência do sistema, sugerindo que se implementem técnicas de motivação e de controle para o uso regular. 


\section{REFERÊNCIAS}

1. Rodrigues AP, Amaral VF, Moro CMC, Bastos LC. Apoio à Educação em Medicina através da Internet. [monografia na Internet]. São Paulo: SBIS; 2006 [acesso em 30 nov. 2007]. Disponível em: http:/ / www.sbis.org.br/cbis/arquivos/1055.pdf.

2. Fichmann S. A gestão transdisciplinar de uma comunidade virtual de aprendizagem: Projeto Telemar Educação. São Paulo; 2005 Mestrado [Dissertação] - Universidade de São Paulo.

3. Secretaria de Comunicação Social da Presidência da República [homepage na Internet]. Brasília: Governo Federal. [atualizada em 23 mai 2007; acesso em 12 ago 2007]. Governo quer expandir ensino superior a distância. Disponível em http://mecsrv04.mec.gov.br/acs/asp/noticias/noticiasId.asp?Id=4907.

4. Rocha JSY, Caccia-Bava MC, Rezende CEM. Pesquisa-aprendizagem no ensino da política e gestão de saúde: relato de uma experiência com e-learning. Rev Bras Edu Med. 2006; 30(1): 73-8.

5. Litto FM. Educação a distância e a USP. Jornal da USP [periódico na Internet]. abril 2003 [acesso em 26 jan 2004]; 639:[aproximadamente 3p.]. Disponível em: http://www.futuro.usp.br/producao_cientifica/artigos/fl_eadeausp.htm.

6. Universidade de Brasília, Faculdade de Medicina, Comissão de Graduação [homepage na Internet] Brasília: UnB; [atualizada em 06 fev 2000; acesso em 12 jan 2004]. Projeto acadêmico-pedagógico, âmbito da graduação, curso de medicina; [aproximadamente 14p.]. Disponível em http://www.unb.br/fm/projfm.doc.

7. Laboratório de teleducação [homepage na Internet]. Porto Alegre: UFRS; [acesso em 23 set 2007]. O Processo de Fabricação de Memória; [aproximadamente 7 telas]. Disponível em http:/ / penta.ufrgs.br/edu/telelab/1/types.htm.

8. Anuário Brasileiro Estatístico de Educação Aberta e a Distância [base de dados na Internet]. São Paulo: Instituto Monitor [acesso em 13 abr 2006]. Disponível em http:/ /www.abraed.com.br.

9. Regulamento do ensino a distância, Pub. Dec. No. 5.622/05, PR (19 dez 2005).

10. Diretrizes e normas regulamentadoras de pesquisas envolvendo seres humanos, Pub. Res. No. 196/96, MS, CNS (10 out 1996).

11. Latin American and Caribbean Internet Addresses Registry [base de dados na Internet]. Montevideo: LACNIC. [acesso em 12 abr 2007]. Disponível em http:/ / www.lacnic.net.

12. Coeli CM, Almeida LM, Rocha TCG, Camargo Júnior KR. Epidemio online: um site de apoio ao processo de ensino-aprendizagem de epidemiologia na graduação de medicina. Rev Bras Edu Med. 2004; 28(3): 259-63.

13. Silva RB. Metodologia - para os alunos que desejam estudar de verdade [monografia na internet] Florianópolis: UFSC; 2002 [acesso em 16 out 2007]. Disponível em http:/ / www.arq.ufsc.br/urbanismo1/metodologia.pdf.

14. Peruccini R. Tempo para tudo. São Paulo: Madras Business; 2001.

15. Greenhalgh T. Computer assisted learning in undergraduate medical education. Brit Med J. 2001; 322, 40-4.

\section{CONFLITO DE INTERESSES}

Declarou não haver

\section{ENDEREÇO PARA CORRESPONDÊNCIA}

Malthus Fonseca Galvão

Universidade de Brasília

Faculdade de Medicina - Área de Patologia

CEP. 70910-900 - Brasília - DF

E-mail: malthus@malthus.com.br 